\title{
La búsqueda de la trascendencia en La lección de pintura de Adolfo Couve
}

\author{
The search for transcendence in \\ La lección de pintura by Adolfo Couve
}

Roberto Angel G.

Pontificia Universidad Católica de Valparaíso. Valparaíso, Chile

rangel@uc.cl

... construía su verso con el agónico aliento de quien, minuto a minuto, sufría la avidez de los sentidos. Porque el mundo era para él, como para los elegidos por el arte, la última oportunidad (Alí Chumacero).

Ta lección de pintura (Adolfo Couve, 1982 [1979]), es posible de leer como un fugaz viaje que da cuenta del nacimiento y desarrollo de un artista, en este caso un pintor, Augusto, desde su despunte en la zona rural de Morandé, hasta la entrada a su adolescencia, momento en el cual su genio y talento estarían, eventualmente, a punto de estallar.

A partir de lo anterior, primero realizaré un recorrido de las características más usuales y relevantes, dentro de La lección de pintura, que responden y problematizan la pregunta “¿qué es ser un artista?”, para continuar con el análisis propiamente tal, de la cosmovisión del arte dentro de la novela, la cual se inclinaría hacia una manifestación realista, cuyo fin teleológico sería la búsqueda de la trascendencia.

Los artistas, en general, siempre han sido vistos como seres distintos, que poseen algo diferente en relación al resto de los individuos. Tal como señala Francisco Calvo en su ensayo Lo novelesco y lo novelado de la vida de los ar- 
tistas, “... los artistas, y no cualquier otra clase de profesionales, forman una raza aparte del resto de la humanidad... se creó una imagen típica... en la mente de la gente" (1991: 53), es decir, se han establecido ciertas cualidades que identifican la manera de ser de los artistas dentro de la sociedad.

Una de las primeras nociones que pone de manifiesto La lección de pintu$r a$, con respecto a la concepción del artista, es la idea de que éste nace como tal y no requiere de ningún tipo de enseñanza que guíe de alguna forma su camino hacia la consumación de su estrella ${ }^{1}$.

Es así como Augusto, en una de las múltiples visitas que efectúa a su autoproclamado protector, el farmacéutico Aguiar, lleva a cabo, sin recibir instrucción alguna, una verdadera obra maestra, lo cual no deja indiferente a su benefactor, que sorprendido observa ante sí la presencia de un prodigio:

A punto estuvo de caer desmayado. Sus ojos no cesaban de ir de la acuarela al cuadro que colgaba del muro. Lo que tenía entre sus manos era una pequeña obra maestra, de una perfección técnica increíble.

-¡Dios Santo, este niño es un genio! -exclamó con la boca abierta, mientras no atinaba sino a apoyarse contra el muro (38-39).

La misma situación vuelve a repetirse, esta vez frente a Lucrecia, la profesora de arte del curso de pintura de verano en el cual Aguiar inscribe a Augusto, con el objetivo de que comience con sus estudios formales.

En esta parte del relato, Augusto vuelve a demostrar sus condiciones innatas, deslumbrando a su preceptora con un dibujo cuya "construcción era perfecta, y el achurado del claroscuro tan transparente que tenía la calidad de la obra de un maestro" (67).

De aquí en más, el ahora joven Augusto continuará con sus estudios, pero siempre confiando en sus propios juicios y apreciaciones, sin considerar las opiniones de Lucrecia y "haciendo oídos sordos a sus cuentos,... [buscando] afanosamente la perfección formal de los pintores neoclásicos que tanto lo seducían" (72), transformándose de esta manera en su propio maestro, ya que, como al fin comprende, "el corazón de un artista era inconfundible" (81), conociendo "por primera vez la soledad que aguarda en este

${ }^{1}$ Es preciso señalar que en La comedia del arte, novela posterior de Adolfo Couve, también se lleva a cabo, pero de forma más reducida, este mismo motivo o tema, esta vez en la figura de Sandro, el joven pintor que se apropia de los materiales de Camondo y que gracias a su talento innato, dejando de lado cualquier tipo de enseñanza, alcanza la cima del arte a través de sus cuadros y su pintura. 
mundo a los más afortunados" 2 (82).

De este modo, Augusto desplegará sus dotes a lo largo de la novela, sin tomar en cuenta lo que ninguno de sus tres modeladores -Aguiar, De Morais y Lucrecia- digan o entiendan como reglas para definir el arte. Por el contrario, Augusto parecerá no sólo seguir un sendero propio, sino opuesto, al complacerse con la visión y ejecución de los pintores neoclásicos, tales como Monvoisin, Word, Searle y Rugendas, en desmedro de las positivas opiniones que dan Aguiar y su maestra, referentes a las nuevas tendencias vanguardistas que proliferaban en la época. Al respecto, Aguiar le dirá: “Aquello es pintura neoclásica, literatura, porquería, basura! ¡Escuela enemiga de los pintores románticos e impresionistas! Artistas libres, sanos, de la luz y del paisaje" (47).

Esta disputa presente dentro de las páginas de La lección de pintura, es posible de comprender mejor si consideramos que el propio Couve hacía suya esta controversia. Tal como escribe Ignacio Valente (1980), refiriéndose al autor de esta breve novela, "este quijote... sigue empeñado, a contrapelo del tiempo y del espacio, en escribir una prosa flaubertiana e intemporal, muy depurada", recalcando así la tendencia artística adoptada por Couve, es decir la veta realista.

El origen de esta elección estaría enmarcado en un aura melancólica que rodea la obra del escritor chileno. Tanto en su faceta de pintor como de narrador, las obras de Couve suelen estar acompañadas por una nostalgia del paraíso perdido - aquella infancia remota, de ahí la gran cantidad de niños que aparecen en sus relatos- y del inexorable paso de los años, es decir, del vislumbre de la muerte.

La manera que Couve tiene para contrarrestar esta angustia, es el cultivo del arte a través del realismo, ya que es la forma de abstraer del impacto del transcurso del tiempo, tanto a los objetos como a los seres inmersos en la realidad. En efecto, es el propio Couve el que aclara esta postura:

Claro, el realista le tiene mucho miedo a la muerte, tiene periodos de muchas depresiones y angustias, y se afirma entonces en estas ecuaciones de perfección, síntesis, economía de medios, de búsqueda de la esencia de las cosas, para poder creer en algo y para poder rescatar del tiempo lo que

${ }^{2}$ Cabe destacar aquí el hecho de que el propio Couve pareciera haber vivido su experiencia como artista bajo un halo de soledad muy determinante. En relación a esto, en una entrevista preparada por María Elena Aguirre, es el mismo autor de La lección de pintura quien declara: "Soy afortunado en este mundo porque vivo en soledad. Es la soledad de ser testimonio de la época sin estar involucrado en los hechos" (1980). 
sucede con las personas con el tiempo; el realista le tiene terror al desgaste (Couve, entrevista de Cristián Warnken).

Para esto, el artista debe traducir y no copiar la realidad, hallar el temple universal de las cosas, como Augusto, quien al pintar sus bocetos, "trasladaba de lugar una realidad” (44), o sea, y tal como efectúa acérrimamente Couve en La lección de pintura, por medio de la descripción ${ }^{3}$, revelar los objetos, su alma, con el propósito de capturarlos y aislarlos del paso del tiempo.

Así, el artista congelaría la eternidad de los momentos (de ahí que Couve pueda señalar "que los grandes artistas viven la eternidad desde aquí"), con lo que tendría acceso a la consumación del arte, es decir, a la divinidad.

Sí, porque para Couve el arte es una religión, pues para él "el arte... es uno de los tantos caminos para llegar a Dios, camino de conversión, camino hacia la Luz" (Aguirre, 1980).

Por consiguiente, el artista deviene un mensajero, el cual por medio de su don, otorgado por Dios, se acerca un poco más hacia el conocimiento. Sin ir más lejos, cabe recordar dentro de La lección de pintura, que cuando Aguiar le comunica a Elvira, madre de Augusto, su beneplácito para la aceptación del muchacho, al retornar a su hogar ella cree observar nuevamente sobre una deslavada cruz, la imagen de un Cristo que se había disuelto, insinuando mediante este matiz, que el pequeño estaba protegido por la esencia divina, tal como también plantea agudamente Cristián Montes en su ensayo "La idea de arte y artista en La lección de pintura de Adolfo Couve" (2008).

Para materializar el encuentro con lo eterno, el artista debe practicar una búsqueda de la belleza, la cual para Couve no se halla sino en la sencillez y en la pobreza:

La belleza no es la idea que tenemos de ella. Es más áspera, tosca, no fatiga, no es esplendorosa. Es algo que está más cerca de lo cotidiano, de la taza, de la pobreza. Chaplin es la belleza misma; Greta Garbo, también. La belleza tiene algo amargo, doloroso, aparece en lo modesto y en lo mínimo. Hay más belleza en la provincia que en la capital, más en la población. Cuando el tiempo ha hecho su acción, hay belleza (Montes, 2008).

Esto es exactamente lo que se aprecia en La lección de pintura, en donde Augusto, de origen humilde -lo que recalca aún más este planteamiento-,

${ }^{3}$ Aquí cabe señalar el epíteto con que Justo Pastor Mellado se refiere a nuestro autor en su artículo Sobre Couve, en donde lo nombra como el "narrador total que pasea su ojo por todo el universo". Así, Couve alcanzaría "la picturalización de la escritura” (2002). 
prefiere quedarse "en los modestos boliches de su barrio, rodeado de campesinos, dibujando en un grasiento papel de envolver que apoyaba sobre la tapa de un barril" (43). Es así como la pobreza se convierte en una "justa ordenadora y coleccionista de objetos adecuados... colores profundos y composiciones caprichosas, como allí, junto a las papas y a las frutas, que se destacaban nítidas del hollín y la pátina de los muros" (43).

Siguiendo esta misma línea se encuentra la preferencia de Couve, tal como señala otra vez Montes, por los espacios rurales, alejados del brillo y de la gran ciudad. El mismo Couve señala al respecto: "La lección de pintura... rescata para Chile la provincia, ese mundo informal y lleno de simpatía, que es tan importante. La provincia es la Universidad del artista" (Larraín, 1989).

En este marco, resulta natural que el pequeño Augusto desarrolle toda su niñez en una minúscula localidad aledaña al pueblo de Llay-Llay, cuya atmósfera estará siempre circundada por aquel ambiente pueblerino, tan propicio, en este caso, para su crecimiento como artista.

En resumen, podemos decir que la novela da cuenta de una de las propiedades más relevantes a la hora de definir a un artista: su capacidad de ser autodidacta y de descubrir, a través de sus propios medios, la senda del arte.

Además, Couve lleva a cabo, por medio de su relato, una defensa del realismo, tanto en materia de pintura como de escritura, en contraposición con las nuevas técnicas de vanguardia, que se alejan de una pulcra descripción y de una economía de medios para acometer sus obras.

Finalmente, lo que Couve pretende entregar con La lección de pintura es lo que él mismo denomina "una lección de vida", ya que es por medio de este arte realista que el ser humano podría acceder a lo eterno, aquel lugar en donde se encontraría Dios y, de paso, el conocimiento.

\section{REFERENCIAS}

Aguirre, María Elena. (1980). "Soy afortunado en este mundo porque vivo en soledad", entrevista a Adolfo Couve. El Mercurio, 10 de febrero. Disponible en http://www.letras.s5.com/archivocouve.htm.

Calvo Serraller, Francisco. (1991). Lo novelesco y lo novelado de la vida de los artistas. Revista de Occidente, 117, 47-60.

Couve, Adolfo. (1982) [1979]. La lección de pintura. Santiago, Chile: Pomaire.

(1995). La comedia del arte. Santiago, Chile: Alfabeta Impresores. 
Larraín, Ana María. (1989). "La vida mía se la he ofrendado al arte", entrevista a Adolfo Couve. Revista de Libros de El Mercurio 20 de agosto. Disponible en http://www.letras.s5.com/archivocouve.htm.

Montes, Cristián. (2008). La idea de arte y artista en La lección de pintura de Adolfo Couve. Anales de Literatura Chilena, 10, 119-135. Disponible en http://www.uc.cl/letras/html/6_publicaciones/pdf_revistas/anales/ a10_9.pdf.

Pastor Mellado, Justo. (2002). Sobre Couve. Disponible en http:// www.justopastormellado.cl/escritos_cont/semanal/2002/08_agosto_2002/20020820.html.

Valente, Ignacio. (1980). Adolfo Couve: La lección de pintura. El Mercurio, 16 de marzo. Disponible en http://www.letras.s5.com/archivocouve. htm.

Warnken, Cristián. (Sin fecha). "Los grandes artistas viven la eternidad aquí", enttrevista a Adolfo Couve, Canal ARTV. Disponible en: http:// www.letras.s5.com/archivocouve.htm. 